\title{
Preparation of Composite Particles Made of Biodegradable Polymer and a Few Additives with Phase Separation Followed by Drying-in-Liquid
}

\author{
Mitsuru Kutsuwada, Yoshinari Taguchi, Masato Tanaka* \\ Graduate School of Science and Technology, Niigata University, Niigata, Japan \\ Email: "tanaka@eng.niigata-u.ac.jp
}

Received 20 January 2015; accepted 6 February 2015; published 9 February 2015

Copyright (C) 2015 by authors and Scientific Research Publishing Inc.

This work is licensed under the Creative Commons Attribution International License (CC BY). http://creativecommons.org/licenses/by/4.0/

\section{(c) (i) Open Access}

\begin{abstract}
It was tried to prepare the biodegradable composite particles by the phase separation method followed by the drying-in-liquid method. The composite particles were made of poly- $\varepsilon$-caprolactone, quaternary ammonium, carbon black and wax. In the experiment, acetone and water were selected as a good solvent and a poor solvent for poly- $\varepsilon$-caprolactone, quaternary ammonium and wax, respectively. The composite particles were prepared by changing the surfactant species and their concentration, the feeding velocity of water and the weight ratio of poly- $\varepsilon$-caprolactone with larger molecular weight to one with smaller molecular weight. The composite particles with the inner structure in which carbon black, quaternary ammonium and wax were coated well with poly- $\varepsilon$-caprolactone could be prepared by the preparation method presented in this study. The structure and the mean diameter of composite particles were strongly affected by the feeding velocity of water. The higher the feeding velocity of water, the larger the mean diameter of composite particles. The mean diameter was drastically decreased with the surfactant concentration and increased with the added amount of poly- $\varepsilon$-caprolactant with larger molecular weight.
\end{abstract}

\section{Keywords}

Biodegradable Composite Particles, Phase Separation, Drying-in-Liquid, Poly- $\varepsilon$-Caprolactone, Microencapsulation

\footnotetext{
${ }^{*}$ Corresponding author.
} 


\section{Introduction}

Many kinds of composite particles have been prepared by various preparation methods and applied in many fields such as information recording materials, paintings, writing materials, adhesive, cosmetics, food industry, medicine and so on [1] [2]. These composite particles could be prepared by using inorganic, organic and polymeric materials and by combining these elementary materials. We can give a single composite particle of several functions by selection and combination of materials used to prepare [1] [2].

However, on a few practical application fields of these composite particles, it is strongly desired that the composite particles are prepared by using biodegradable materials [3]-[6]. For an example, it has been tried to prepare microcapsules or composite particles, which contain agricultural medicine or pheromone for noxious insects, by biodegradable materials based on natural elemental materials, because it may be expected that the biodegradable shell materials should vanish after complete release of core material and environmental pollution could be prevented [7]-[9].

Furthermore, the composite particles containing various drugs and physiological active materials dosed into the human body are inevitably required to be biodegradable [10]-[12]. For these demands, the various composite particles have been prepared by using edible and biodegradable materials. Similarly, it has been tried to develop the preparation method of toner used on the copying press with the green preparing process by using biodegradable materials [13]-[15].

In these works stated above, the most important purpose is to develop the simple preparing methods without much energy and noxious volatile solvents. However, it is well known that there are many important things required to be solved in these works. For examples, the noxious solvents have been used as the solvent for biodegradable polymers and the complicated preparation processes have been developed.

In this study, taking these into consideration, we have tried to develop the simple preparation method without any noxious solvents. For this purpose, we have adopted the phase separation method followed by the drying-inliquid method to prepare the biodegradable composite particles, in which poly- $\varepsilon$-caprolactone was used as the biodegradable polymer, because poly- $\varepsilon$-caprolactone with lower melting point $\left(\mathrm{ca} .60^{\circ} \mathrm{C}\right)$ is pliable and easily dissolved in acetone of an innoxious solvent.

The purposes of this study are to investigate whether the biodegradable composite particles could be prepared by the phase separation method [16]-[18] followed by the drying-in-liquid method [1] [19] or not, to establish the optimum operational conditions for preparing the biodegradable composite particles, to characterize the composite particles prepared and to get the fundamental information for application to toner particles.

\section{Experiment}

\subsection{Materials}

Two kinds of biodegradable poly- $\varepsilon$-caprolactone (PCL) (Tokyo Kasei Co., Ltd.) were used as matrix polymer of composite particles. One of them is p- $\varepsilon$-caprolactone (RPCL) with molecular weight of 10,000 and the other p- $\varepsilon^{-}$ caprolactone (HPCL) with molecular weight of $7 \times 10^{4}-10^{5}$. Acetone (Junsei Chemical Co., Ltd.) was used as the good solvent for poly- $\varepsilon$-caprolactone. As additive materials, quaternary ammonium (QA) as a charge controlling agent (Oki Data Co., Ltd.), wax with the melting point of $\mathrm{M}_{\mathrm{T}}=69^{\circ} \mathrm{C}$ and carbon black (CB) (Mitsubishi Chemical Co., Ltd.) were added. Polyoxyethylenesorbitanmonolaurate (Tween20), Polyoxyethylenesorbitantristearate (Tween65) and Polyoxyethylanesorbitanmonooleate (Tween80) (Tokyo Kasei Co., Ltd.) were used as water soluble surfactants.

\subsection{Preparation of Composite Particles}

Figure 1 shows the flow chart for preparing the composite particles made of biodegradable polymer and a few additives.

At first, PCL, Wax, QA and surfactant of a given amount were added into acetone and completely dissolved to form the uniform solution by stirring for 30 min with the six bladed disc type impeller. Next, the CB slurry with $5 \mathrm{wt} \%$ concentration was prepared by adding CB of a given weight into water.

After the CB slurry was poured into the acetone solution, the mixture was homogenized for 3 min with the ultrasonic homogenizer in order to untie bloc of $\mathrm{CB}$ and then, homogenized further for 3 min with the rotor stator homogenizer to completely disperse CB in the solution. Here, it was confirmed that PCL, QA and wax dissolved 


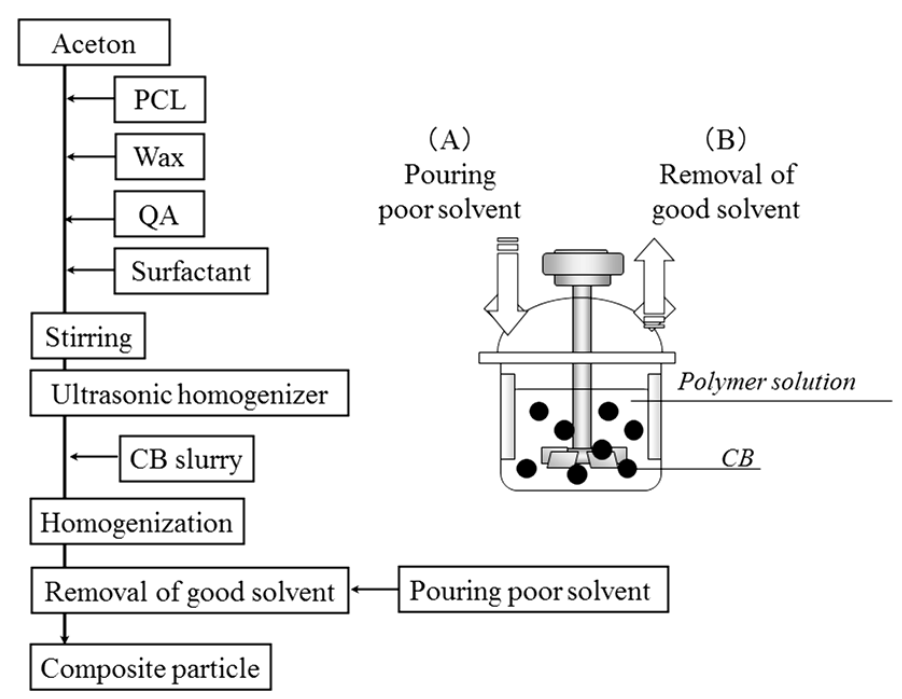

Figure 1. Flow chart for preparing composite particles.

in the acetone solution were not educed by addition of the CB slurry because of small quantity of slurry water $\left(3.5 \mathrm{~cm}^{3}\right)$.

Then, water as the poor solvent was added at the constant feeding velocity by the microfeeder. Then, acetone was removed under the conditions of $\mathrm{T}=30^{\circ} \mathrm{C}$ and low vacuum due to aspirator (drying-in-liquid operation) on pouring water of the poor solvent for PCL. With elapsing time, PCL, wax and QA dissolved in the acetone solution were gradually separated to form coagulums in which CB was contained and to finally form the composite particles.

The drying-in-liquid operation was continued for $3 \mathrm{~h}$ to completely remove acetone. Accordingly, the diameters of composite particles were kept constant at the complete removal of acetone. The composite particles thus formed were separated with the filtration paper and dried under room temperature.

In this operation, the concentration of surfactant $\left(\mathrm{C}_{\mathrm{E}}\right)$, the feeding velocity $\left(\mathrm{V}_{\mathrm{P}}\right)$ of poor solvent (water) and the weight ratio $\left(\mathrm{R}=\mathrm{W}_{\mathrm{H}} / \mathrm{W}_{\mathrm{L}}\right.$ ) of HPCL to RPCL were mainly changed, where $\mathrm{W}_{\mathrm{H}}$ and $\mathrm{W}_{\mathrm{L}}$ were the weights of HPCL and RPCL, respectively. Table 1 shows the experimental conditions adopted in this study.

\subsection{Characterization}

\section{Thermal visco-elasticity}

Thermal visco-elasticity of matrix polymer of composite particles is one of the important characteristics of the composite particles. Especially, when the composite particles are planned to apply to toner particles, it is necessary to obtain the fundamental informations about thermal visco-elasticity of matrix polymer. Thermal viscoelasticity of composite particles was measured by Thermal Visco-Elasticity Instrument (SII Nano Technology Co., Ltd., Japan). Namely, thermal visco-elasticity was measured by changing the weight ratio of HPCL to RPCL.

\section{Observation}

The composite particles formed were observed by optical microscope (OLYMPUS Co., Ltd., Japan) and scanning electron microscope (SEM: Nihon Densi Co., Ltd., Japan), respectively. The inner structure of a composite particle was observed by transmission electron microscope (TEM: Nihon Densi Co., Ltd, Japan). In this observation, the cross section was colored by Lutenium dye.

\section{Diameter distribution and mean diameter}

The diameter distributions and mean diameters of composite particles were measured by Particle Size Analyzer (ELSZ-2; OTSUKA ELECTRONICS Co., Ltd., Japan). Here, the mean diameters were the Sauter mean diameters.

\section{Zeta potential}

As zeta potential of each component in the solution is the important factor to determine whether the composite particles could be prepared or not, zeta potential was measured with Particle Size Analyzer (ELSZ-2: OTSUKA ELECTRONICS Co., Ltd., Japan). 
Table 1. Experimental conditions.

\begin{tabular}{cc} 
Acetone (good solvent) & $220 \mathrm{~g}$ \\
Water (poor solvent) & $250 \mathrm{~g}$ \\
PCL & $2 \mathrm{~g}$ \\
Pigment 5 wt\% (CB slurry) & $4 \mathrm{~g}\left(3.5 \mathrm{ml} \mathrm{H} \mathrm{H}_{2}\right)$ \\
Quaternary ammonium (QA) & $0.02 \mathrm{~g}$ \\
Wax & $0.1 \mathrm{~g}$ \\
Surfactant (Tween20, 65, 80) & $\mathrm{C}_{\mathrm{E}}=2.5-5.5 \mathrm{wt} \%$ \\
Feeding velocity of water & $\mathrm{V}_{\mathrm{P}}=2-6.5[\mathrm{ml} / \mathrm{min}]$ \\
Weight ratio of HPCL to RPCL & $\left.\mathrm{R}_{\mathrm{W}} \mathrm{W}_{\mathrm{H}} / \mathrm{W}_{\mathrm{L}}\right)=0 \%-100 \%$ \\
Homogenization with ultrasonic & $3 \mathrm{~min}$ \\
Homogenization with rotor stator & $3 \mathrm{~min}, 10,000 \mathrm{rpm}$ \\
Temperature of drying-in-liquid process & $\mathrm{T}=30^{\circ} \mathrm{C}$ \\
Time of drying-in-liquid operation & $3 \mathrm{~h}$ \\
Revolution velocity in drying-in-liquid & $250 \mathrm{rpm}$ \\
\hline
\end{tabular}

\section{Results and Discussion}

\subsection{Effects of Surfactant Species and Concentration of Them}

Figure 2 shows the SEM photographs of composite particles prepared with Tween20, Tween65, Tween80. The composite particles prepared with Tween 20 and Tween 65 coagulated each other to form the irregular particles. However, the composite particles prepared with Tween 80 were the spherical sound particles.

As Tween20 (HLB 16.7) is more hydrophilic and Tween65 (HLB 10.5) is more hydrophobic, the stabilizing effect for the $(\mathrm{O} / \mathrm{W})$ emulsion may be lower due to insufficient adsorption amounts of them. Meanwhile, as Tween80 (HLB 15.0) has the optimum HLB, the stabilizing effect for the $(\mathrm{O} / \mathrm{W})$ emulsion may be stronger. However, it is necessary to investigate the stabilizing effect of surfactant species in detail. Taking the results obtained above into consideration, Tween80 was used to prepare the composite particles hereafter.

Figure 3 shows the effect of concentration of surfactant on the mean diameters of composite particles. From this figure, it was found that the mean diameters deceased with the concentration of surfactant and become almost constant $\left(\mathrm{D}_{\mathrm{p}}=8.32 \mu \mathrm{m}\right)$ at $\mathrm{C}_{\mathrm{E}}=3.7 \mathrm{wt} \%$. With increasing the concentration of surfactant, the stability of $\mathrm{CB}$ and composite particles may be increased to form the smaller sound composite particles.

The SEM photograph of composite particles prepared under the conditions of $C_{E}=3.7 \mathrm{wt} \%$ and $V_{P}=2.0$ $\mathrm{ml} / \mathrm{min}$ is also shown in Figure 3. It was found that the composite particles with the mean diameter of about $8.32 \mu \mathrm{m}$ and the dispersion degree $\left(\sigma / \mathrm{D}_{\mathrm{p}}\right)$ of 0.38 could be prepared, where $\sigma$ was the standard deviation of diameter distribution.

\subsection{Effect of Feeding Velocity of Poor Solvent}

Figure 4 shows the effect of feeding velocity of poor solvent on the mean diameter and the morphology of composite particles under the conditions of $\mathrm{C}_{\mathrm{E}}=3.7 \mathrm{wt} \%$ and $\mathrm{R}=0$ (only with RPCL) together with the microscopic photographs. It was found that with increasing the feeding velocity, the mean diameter increases from 30 $\mu \mathrm{m}\left(\mathrm{V}_{\mathrm{P}}=2.0 \mathrm{ml} / \mathrm{min}\right)$ to $290 \mu \mathrm{m}\left(\mathrm{V}_{\mathrm{P}}=6.5 \mathrm{ml} / \mathrm{min}\right)$ and larger coagulated particles come to be formed. Furthermore, CB was found to be coated well with PCL separated by pouring the poor solvent and to form the composite particles. However, wax is not observed well in these photographs. The microscopic photographs in Figure 4 were taken in the slurry. Accordingly, PCL adsorbed on the surface of CB was swollen. For this reason, the diameters shown in Figure 4 become larger than those in Figure 3.

From these results, it was found that the feeding velocity was an important factor to determine the diameter and structure of composite particles. Furthermore, the feeding velocity slower than $4.0 \mathrm{ml} / \mathrm{min}$ was found to be the optimum feeding velocity to prevent from coagulating and to prepare the composite particles with the desired structure. 

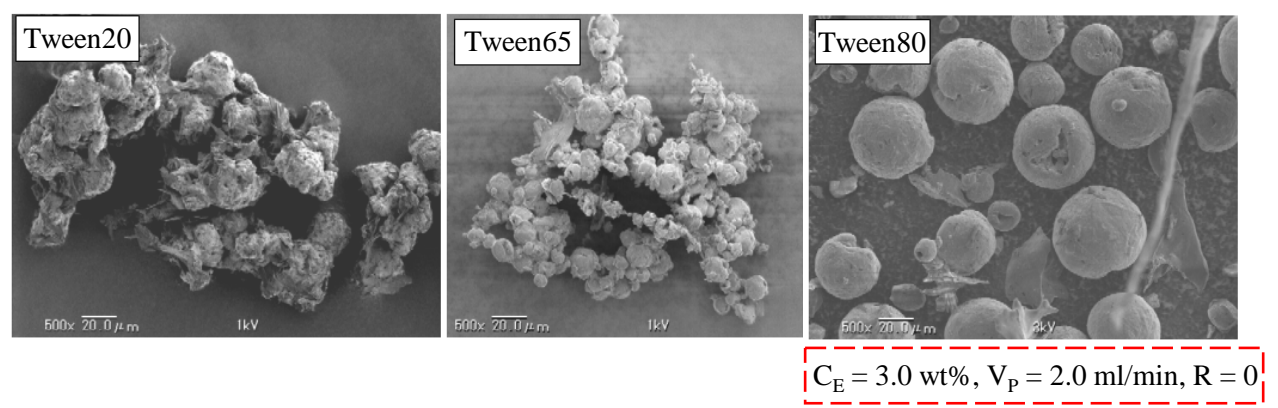

Figure 2. SEM photographs of composite particles (effect of surfactant species).

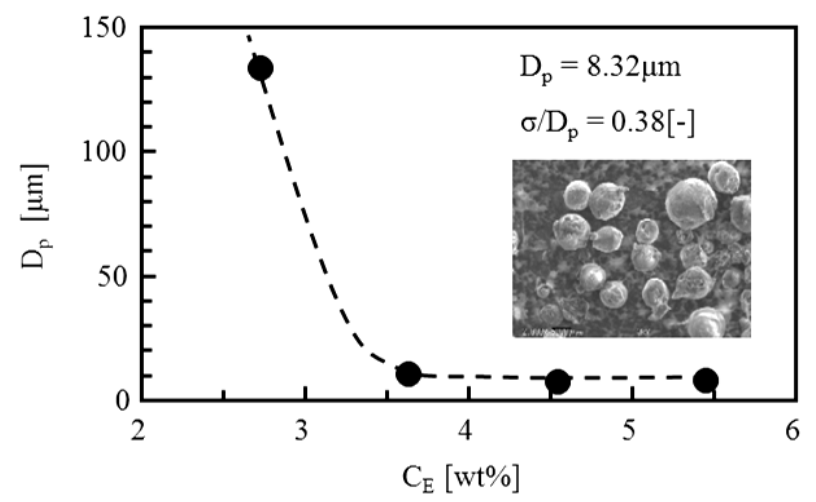

$\left(\mathrm{R}=0, \mathrm{~V}_{\mathrm{P}}=2.0 \mathrm{ml} / \mathrm{min}\right.$, Tween 80$)$

Figure 3. Effect of concentration of surfactant on diameter of composite particle.
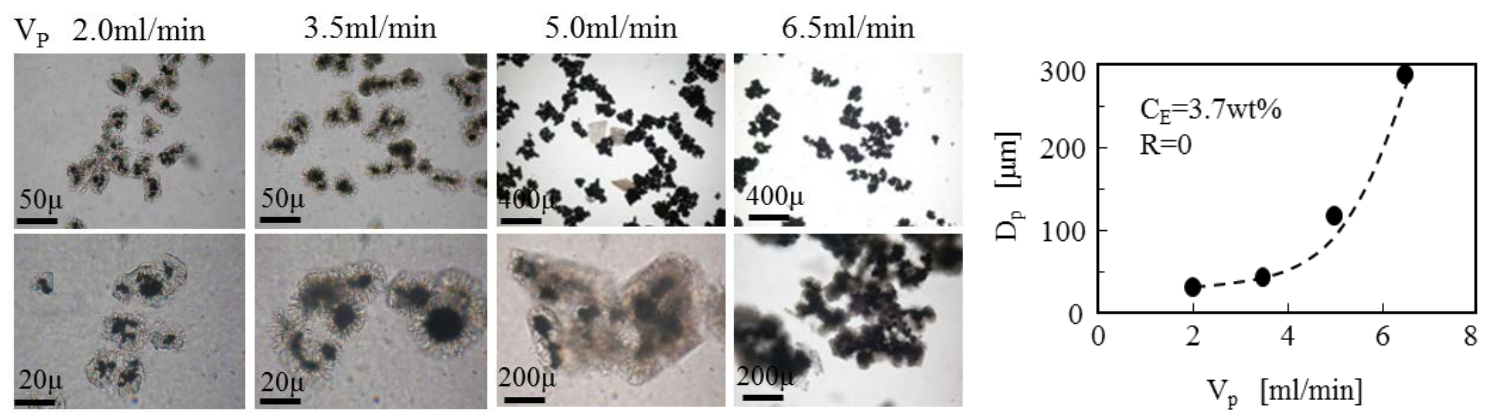

Figure 4. Effect of feeding velocity of poor solvent on formation of composite particles.

\subsection{Effect of Weight Ratio of HPCL to RPCL}

Figure 5 shows the dependence of the mean diameters of composite particles on the weight ratio (R) at each concentration of surfactant. In Figure 5, the mean diameters drastically decreased with the concentration of surfactant even at any ratio. The larger the ratio, the larger the mean diameter. When HPCL dissolved in the oil phase was educed, the larger nuclei were formed and then, the larger particles were formed due to coagulation each other. However, in order to prepare the composite particles with the mean diameter of ca. $10 \mu \mathrm{m}$, it was found that there was the critical concentration of surfactant at each ratio.

For an example, the critical concentrations were $3.5 \mathrm{wt} \%\left(\mathrm{D}_{\mathrm{p}}=10.5 \mu \mathrm{m}\right)$ at $\mathrm{R}=0$ and $\mathrm{R}=10 \%, 7 \mathrm{wt} \%\left(\mathrm{D}_{\mathrm{p}}=\right.$ $10.3 \mu \mathrm{m})$ at $\mathrm{R}=50 \%, 8.2 \mathrm{wt} \%\left(\mathrm{D}_{\mathrm{p}}=10.5 \mu \mathrm{m}\right)$ at $\mathrm{R}=100 \%$, respectively.

Figure 6 shows the SEM photographs and diameter distributions of composite particles prepared under each experimental condition in which both the number distributions and the volume distributions of diameters are also shown. The composite particles are found to be spherical particles. Furthermore, the diameter distributions at $\mathrm{R}=10 \%$ and $100 \%$ were more uniform compared with that at $\mathrm{R}=50 \%$. 


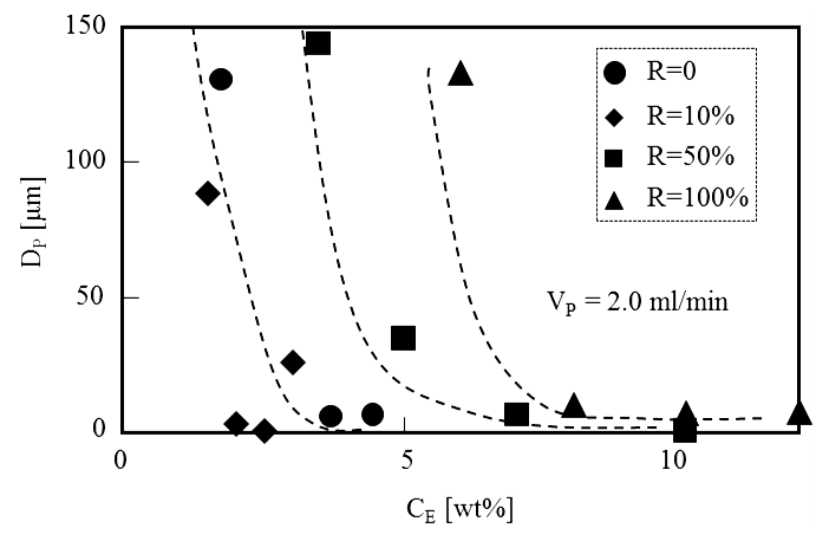

Figure 5. Dependence of mean diameter on concentration of surfactant and weight ratio.

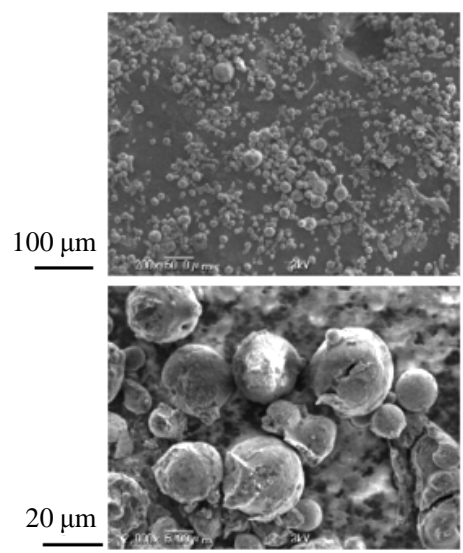

(a) $\mathrm{R}=10 \%, \mathrm{C}_{\mathrm{E}}=2.5 \mathrm{wt} \%$

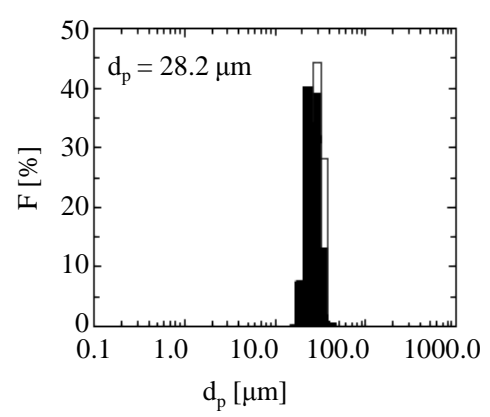

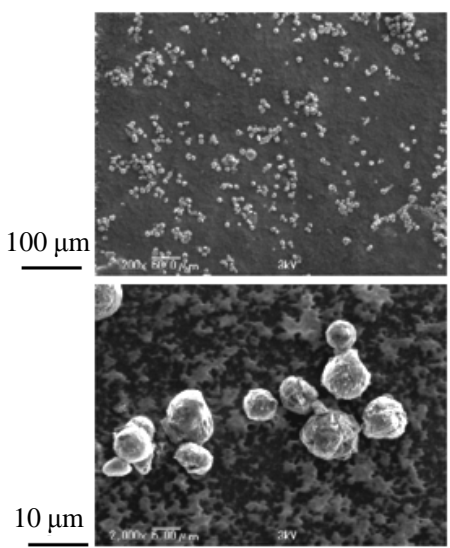

(b) $\mathrm{R}=50 \%, \mathrm{C}_{\mathrm{E}}=7.0 \mathrm{wt} \%$

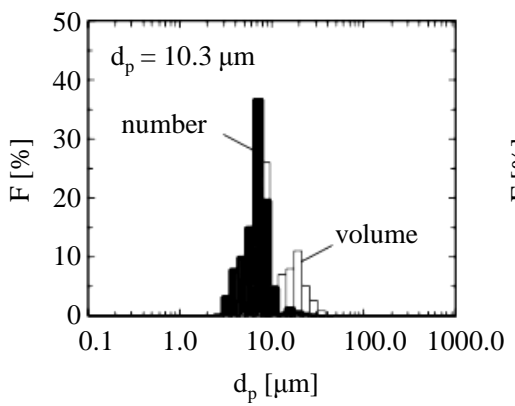

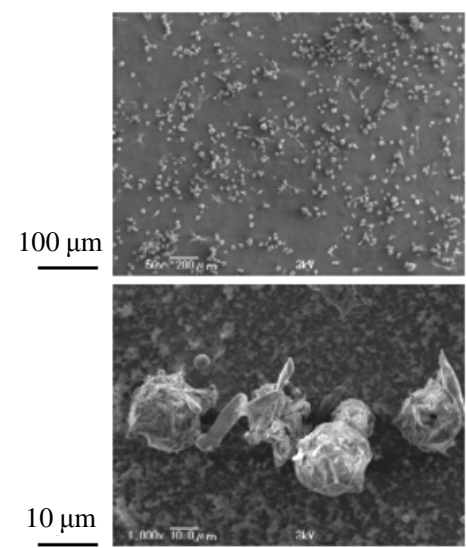

(c) $\mathrm{R}=100 \%, \mathrm{C}_{\mathrm{E}}=8.2 \mathrm{wt} \%$

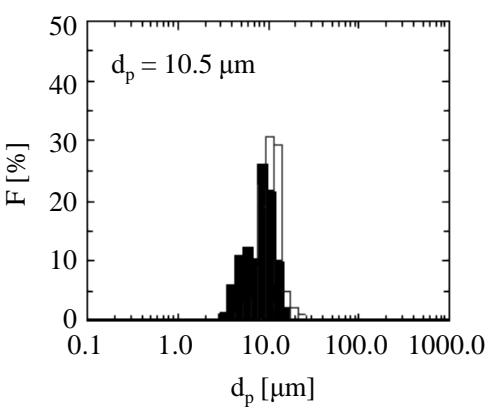

Figure 6. Effect of molecular weight of polymer $\left(\mathrm{V}_{\mathrm{P}}=2.0 \mathrm{ml} / \mathrm{min}\right)$.

\subsection{Thermal Visco-Elasticity}

Figure 7 shows the results of the thermal visco-elasticity of composite particles prepared with RPCL and HPCL together with that of toner particles used on the hard copy for reference. In Figure 7, the curve 1, the curve 2 and the curve 3 are the results for RPCL, HPCL and toner particles, respectively.

If we are going to apply the composite particles made of only RPCL or only HPCL to the toner particles, it may be necessary to modify the thermal visco-elasticity of the composite particles.

Figure 8 shows the results of the thermal visco-elasticity measured by changing the weight ratio of HPCL to RPCL and adding wax. From these results, it was found that the thermal visco-elasticity of composite particles was not affected by the weight ratio of HPCL to RPCL (as shown in Figure 8(a)) and become almost equal to the desired result when the composite particles were prepared with HPCL and wax of $5 \mathrm{wt} \%$ (as shown in Figure 8(b)). Here, L in Figure 7 and Figure 8 is the moving distance of sensor contacting to the sample. 


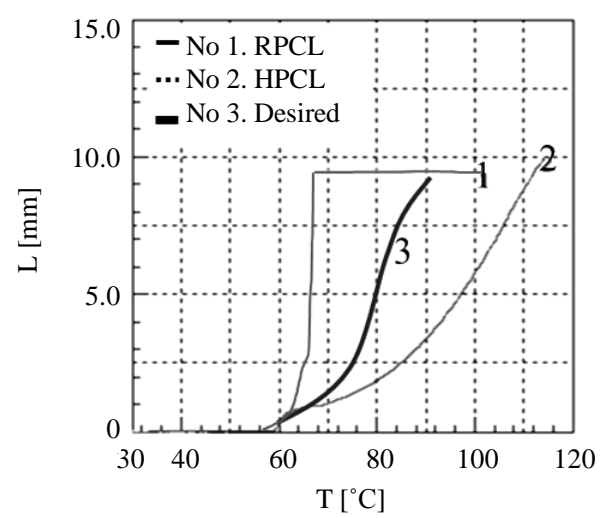

Figure 7. Measured thermal vsico-elasticity of PCL.

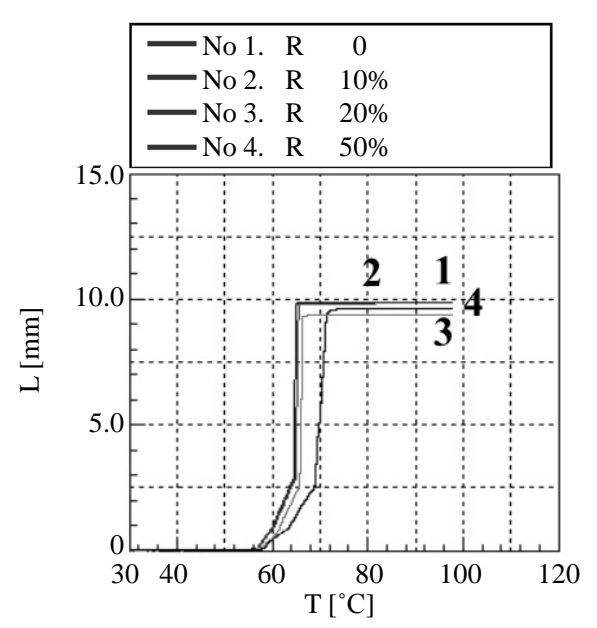

(a)

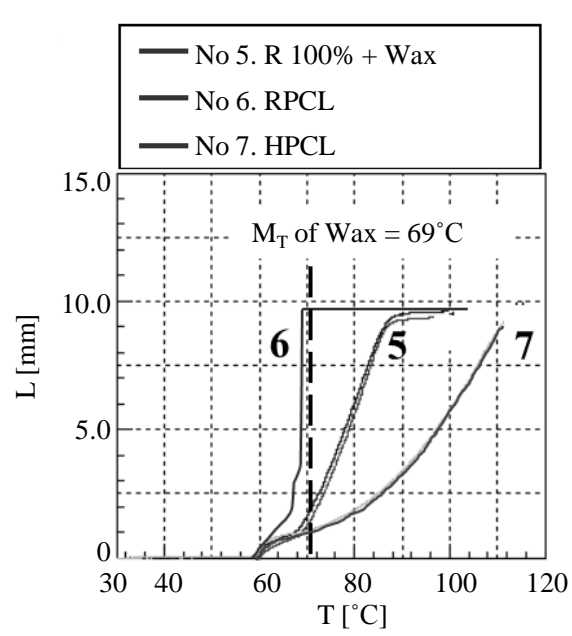

(b)

Figure 8. Effect of weight ratio on thermal visco-elasticity of matrix polymer.

\subsection{Formation Mechanism of Composite Particles}

Figure 9 shows the TEM photographs of the inner structure of composite particles prepared under the conditions as shown in figure, where PCL was colored by lutetium dye. It was found that wax (white color) and CB (black color) were contained well in the matrix polymer. From the results obtained above, the formation mechanism of composite particles may be presented as shown in Figure 10(a). At first, more hydrophobic wax is rapidly separated out and adheres on the hydrophobic surface of CB due to the hydrophilic-hydrophobic interaction and due to attractive force on the basis of zeta potential. The zeta potential of each material measured in the acetone aqueous solution is shown in Figure 11. Next, PCL and QA may adhere on the surface of coagulated particles made of wax and CB due to hetero coagulation, because PCL and QA charge positively and wax charges negatively as shown in Figure 11. Also, the effect of feeding velocity of poor solvent on the diameter and structure may be explained as follows (in Figure 10(b)).

Namely, although CB is contained well into the composite particles at the slower feeding velocity of poor solvent, however, CB comes to coagulate each other by the binder action of PCL rapidly separated at the faster feeding velocity of poor solvent. Finally, the composite particles must be prepared by complete removal of good solvent. As a result, the faster the feeding velocity, the larger the diameters of composite particles.

Here, the selection of acetone of the good solvent and water of the poor solvent for PCL must be the optimum combination, because both solvents are innoxious and generate zeta potential in the dispersion. Also, the revolution velocity of impeller in the drying-in-liquid operation must necessarily affect the composite particle diameter, because coalescence and break-up of droplets are affected by the revolution velocity. Accordingly, if the other solvent species and revolution velocity should be used, the different results should be obtained. 

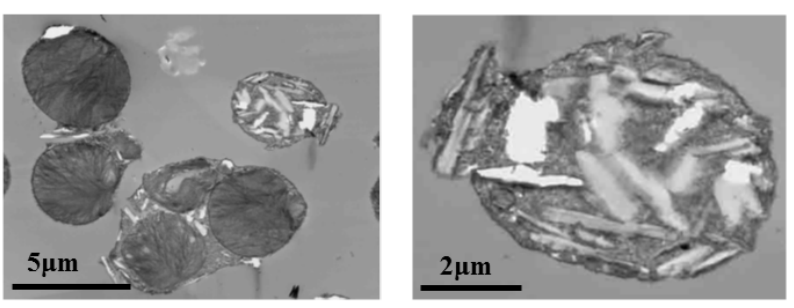

$\left(\mathrm{R}=100 \%, \mathrm{C}_{\mathrm{E}}=8.2 \mathrm{wt} \%, \mathrm{~V}_{\mathrm{P}}=2 \mathrm{ml} / \mathrm{min}\right.$, wax $\left.5 \mathrm{wt} \%\right)$

Figure 9. TEM photographs of composite particles (colored by lutetium).

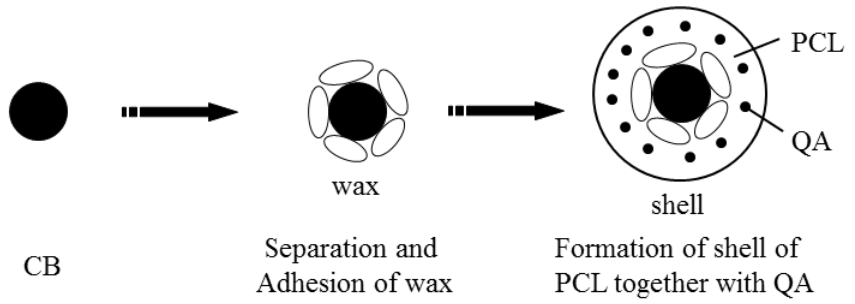

(a)

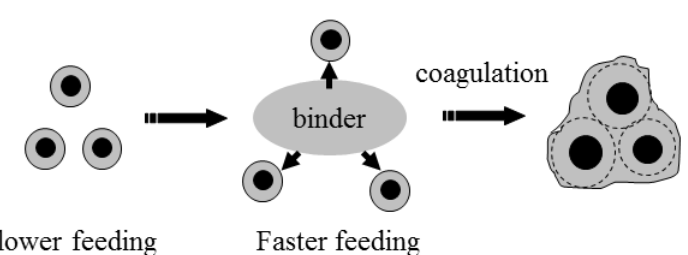

(b)

Figure 10. Formation mechanism of composite particles. (a) Formation of composite particles; (b) Effect of feeding velocity.

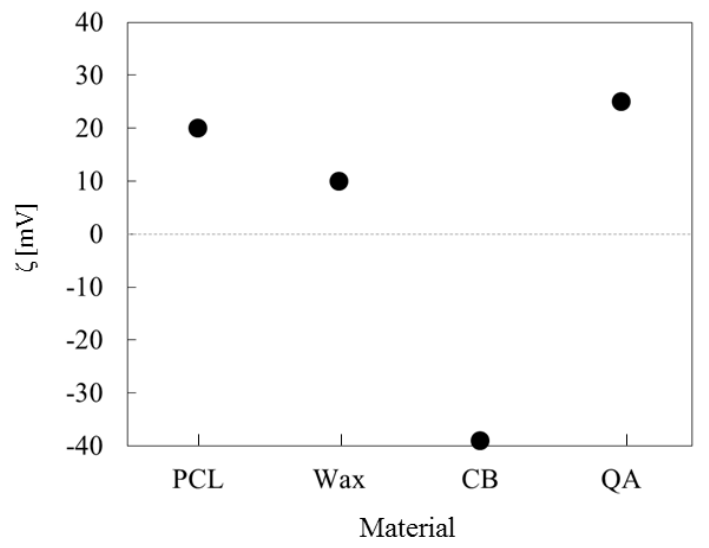

Figure 11. Zeta potential of each material.

\section{Conclusions}

We have tried to prepare the composite particles made of biodegradable polymer, carbon black, quaternary ammonium and wax by the phase separation method followed by the drying-in-liquid operation. The following fundamental results could be obtained.

1) The composite particles could be prepared by the preparation method presented in this study.

2) The structure and the mean diameter of composite particles were strongly affected by the feeding velocity of poor solvent for PCL. The larger the feeding velocity of poor solvent, the larger the mean diameter of compo- 
site particles.

3) The spherical sound composite particles could be prepared with Tween80.

4) The diameters of composite particles drastically were decreased with the concentration of surfactant and increased with the weight ratio of PCL with larger molecular weight to PCL with smaller molecular weight.

5) Thermal visco-elasticity of composite particles became equal to that of toner particles by adding wax of 5 wt\% into PCL with larger molecular weight.

6) Some fundamental information of composite particles required to apply to the toner particles could be obtained. However, it is necessary to investigate how the preparation conditions affect the characteristics of composite particles such as the electric charge density on the surface of composite particles, the printing process and the biodegradability of composite particles.

\section{References}

[1] Kondo, T. (1967) Saishin Maikurokapseruka Gijutsu (Microencapsulation Technique). TES, Tokyo. (In Japanese)

[2] Tanaka, M. (2008) Key Point of Preparation of Nano/microcapsules. Techno System Publishing Co. Ltd., Tokyo.

[3] Sendil, D., Gürsel, I., Wise, D.L. and Hasırc1, V. (1999) Antibiotic Release from Biodegradable PHBV Microparticles. Journal of Controlled Release, 59, 207-217. http://dx.doi.org/10.1016/S0168-3659(98)00195-3

[4] Hong, K. and Park, S. (2000) Preparation of Poly(l-lactide) Microcapsules for Fragrant Fiber and Their Characteristics. Polymer, 41, 4567-4572. http://dx.doi.org/10.1016/S0032-3861(99)00677-1

[5] Zhao, G.H., Liu, Y., Fang, C.L., Zhang, M., Zhou, C.Q. and Chen, Z.D. (2006) Water Resistance, Mechanical Properties and Biodegradability of Methylated-Cornstarch/Poly(vinyl alcohol) Blend Film. Polymer Degradation and Stability, 91, 703-711. http://dx.doi.org/10.1016/j.polymdegradstab.2005.06.008

[6] Lee, J.I. and Yoo, H.S. (2008) Biodegradable Microspheres Containing Poly( $\varepsilon$-caprolactone)-Pluronicblock Copolymers for Temperature-Responsive Release of Proteins. Colloids and Surfaces B: Biointerface, 61, 81-87. http://dx.doi.org/10.1016/j.colsurfb.2007.07.008

[7] Gao, Y.T., Shen, P.Y., Wang, B.H., Lü, S.D., Huang, G.C. and Ho, L.S. (1984) Controlled Release Effect of Insecticide Microcapsules and Their Results in Common Household Insect Pest Control. Journal of Microencapsulation, 1, 307-315. http://dx.doi.org/10.3109/02652048409031543

[8] Hirech, K., Payan, S., Carnelle, G., Brujes, L. and Legrand, J. (2003) Microencapsulation of an Insecticide by Interfacial Polymerization. Powder Technology, 130, 324-330. http://dx.doi.org/10.1016/S0032-5910(02)00211-5

[9] Takahashi, T., Taguchi, Y. and Tanaka, M. (2005) Preparation of Polyurea Microcapsules Containing Pyrethroid Insecticide with Hexamethylene Diisocyanate Uretidione and Isocyanurate. Journal of Chemical Engineering of Japan, 38, 929-936. http://dx.doi.org/10.1252/jcej.38.929

[10] Taguchi, Y., Yamada, Y., Ishikura, Y. and Tanaka, M. (2003) Preparation of Biodegradable Capsules Composed of Paper Fibers by Utilizing Liquid-Liquid Dispersion. Journal of Chemical Engineering of Japan, 36, 1236-1241. http://dx.doi.org/10.1252/jcej.36.1236

[11] Sonia, T.A., Rekha, M.R. and Sharma, C.P. (2011) Bioadhesive Hydrophobic Chitosan Microparticles for Oral Delivery of Insulin: In Vitro Characterization and in Vivo Uptake Studies. Journal of Applied Polymer Science, 119, $2902-$ 2910. http://dx.doi.org/10.1002/app.32979

[12] Naidu, B.V.K. and Paulson, A.T. (2011) A New Method for the Preparation of Gelatin Nanoparticles: Encapsulation and Drug Release Characteristics. Journal of Applied Polymer Science, 121, 3495-3500. http://dx.doi.org/10.1002/app.34171

[13] Rekha, M.R. and Sharma, C.P. (2011) Glutamine-Chitosan Microparticles as Oral Insulin Delivery Matrix: In Vitro Characterization. Journal of Applied Polymer Science, 122, 2374-2382. http://dx.doi.org/10.1002/app.34315

[14] Hirano, N., Shimoyama, A. and Uchizono, A. (1995) Japanese Patent No. 7-70116.

[15] Miyazaki, K., Yanagihori, A., Takahashi, N. and Yamaoka, H. (1996) Japanese Patent No. 8-90927.

[16] Yokoyama, Y., Fuchigami, K., Taguchi, Y. and Tanaka, M. (2013) Preparation of Microcapsules with Liquid Droplet Coalescence Method Followed by Phase Separation. Journal of Encapsulation and Adsorption Sciences, 3, 93-97. http://dx.doi.org/10.4236/jeas.2013.33011

[17] Jiang, A., Fang, X., Yu, Q., Deng, J. and Yang, W. (2012) New Route to Monodispersed Amphiphilic Core-Shell Polymer Nanoparticles: Polymerization of Styrene from $\alpha$-Methylstyrene-Containing Macroinitiator. Journal of Applied Polymer Science, 124, 4121-4126. http://dx.doi.org/10.1002/app.35266

[18] Huang, Z., Wang, C., Li, Y. and Wang, Z. (2012) Controlled Preparation of Core-Shell Polystyrene/Polypyrrole Nanocomposite Particles by a Swelling-Diffusion-Interfacial Polymerization Method. Colloid and Polymer Science, 290, 
M. Kutsuwada et al.

979-985. http://dx.doi.org/10.1007/s00396-012-2663-5

[19] Fuchigami, K., Taguchi, Y. and Tanaka, M. (2008) Preparation of Microcapsules Containing TMBA (1,3,5-Trimethylbarbituric Acid) by the Drying-in-Liquid Method and Its Application. Journal of Applies Polymer Sciences, 110, 21452152. http://dx.doi.org/10.1002/app.28825 
Scientific Research Publishing (SCIRP) is one of the largest Open Access journal publishers. It is currently publishing more than 200 open access, online, peer-reviewed journals covering a wide range of academic disciplines. SCIRP serves the worldwide academic communities and contributes to the progress and application of science with its publication.

Other selected journals from SCIRP are listed as below. Submit your manuscript to us via either submit@scirp.org or Online Submission Portal.
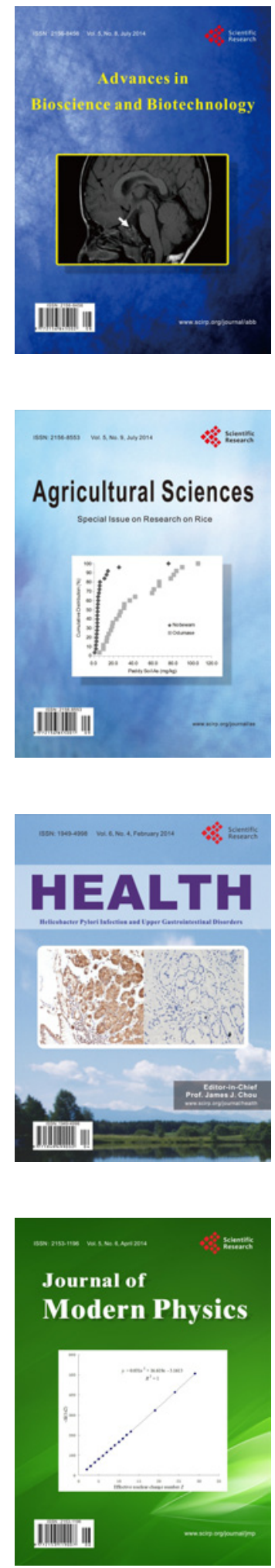
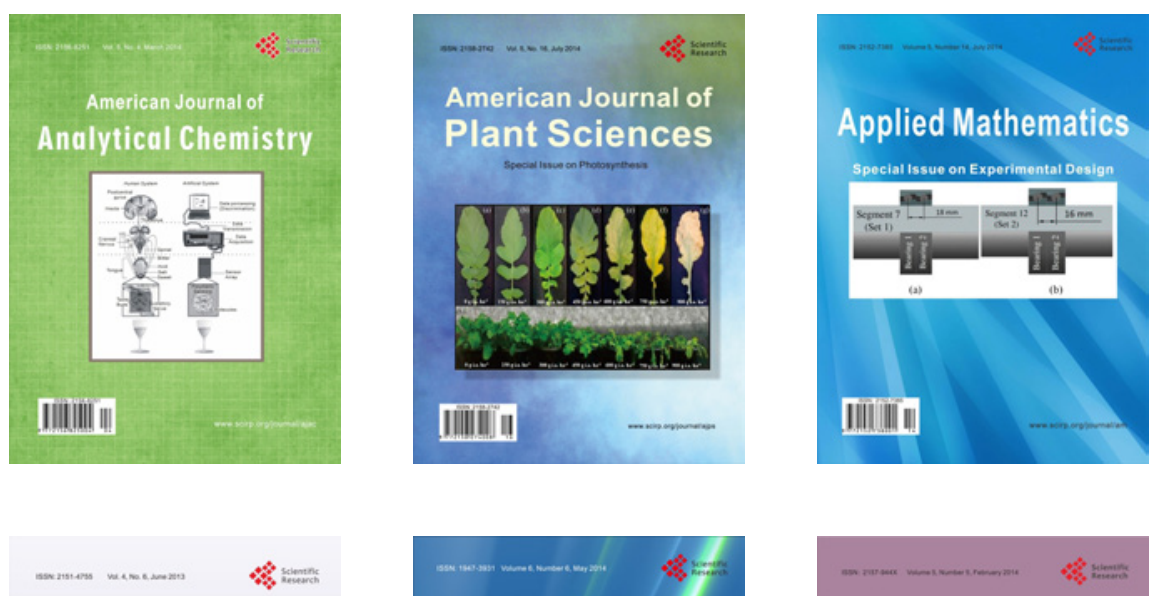

Creative Education
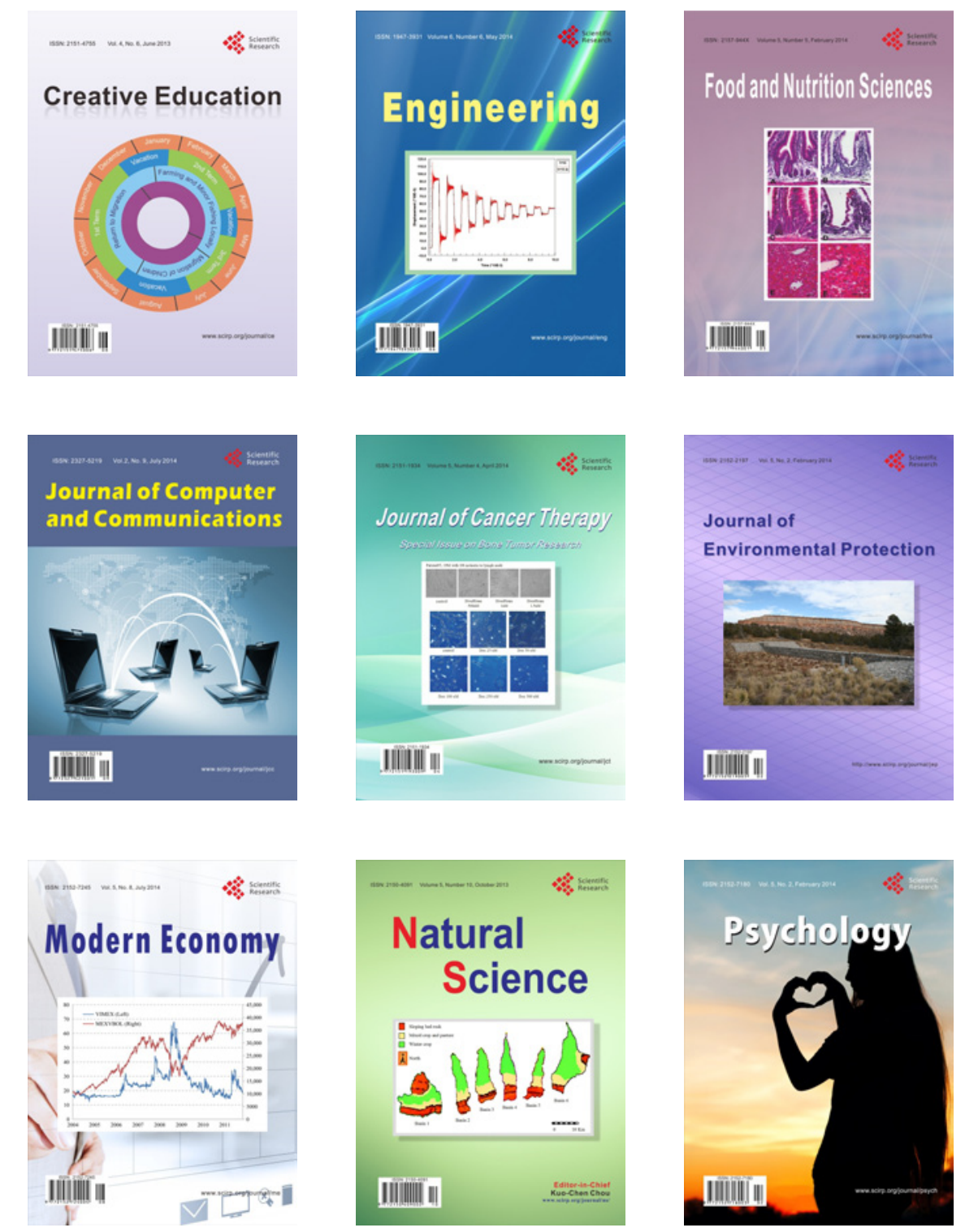